DOI: 10.20472/TEC.2018.005.005

\author{
RADOSTINA MIHALEVA \\ St Kliment Ohridski University of Sofia, Bulgaria
}

\title{
ELABORATION TECHNIQUES IN A SUGGESTOPEDIC FOREIGN LANGUAGE CLASS
}

\begin{abstract}
:
The present article deals with the elaboration techniques of Suggestopedia-Desuggestopedia in particular, and provides practical hints to foreign language teachers who are willing to make their lessons intriguing as well as effective in terms of language acquisition. As adult students are often very sensitive to their own mistakes and find it difficult to overcome the psychological barriers which prevents them from freely expressing themselves in the foreign language, Suggestopedia-Desuggestoedia comes to the rescue by introducing some very effective elaboration techniques which will turn the learning process into a project-game full of numerous, pleasant games and exercises, which students do not perceive as drills. The Suggestopedic elaboration techniques always provide a double-plan view point.
\end{abstract}

\section{Keywords:}

Suggestopedia, Desuggestopedia, Elaboration Techniques, Dr. Georgi Lozanov, the Bulgarian Method

JEL Classification: 129 


\section{Introduction}

Suggestopedia-Desuggestopedia was born in the 1966 at the Institute of Suggestology and Personal Development founded by the Bulgarian scientist, theoretician, psychologist, psychotherapist, neurologist, pedagogue and explorer, Dr. Georgi Lozanov, in Sofia, Bulgaria, as a new humanistic methodology of teaching foreign languages to adults. After contemplating over the tremendous positive effects of normal communication in a number of clinical cases at hospital in his clinical practice, as well as after numerous experiments of memorizing lists of new words by different groups of learners who have been given different stimula, Dr. Lozanov and his associates came to the conclusion that the hidden reserves of the brain can be well made use of in foreign language teaching. So his team of teachers, psychologists, pedagogues, and technicians under Dr. Lozanov's guidance took to exploring an area which was not yet at the time explored. Today SuggestopediaDesuggestopedia is known on all continents and Dr. Lozanov's disciples and followers fervently work for popularizing its positive outcomes of both quick acquisition of foreign languages and tremendous therapeutic effect on the students.

To start with, Suggestopedia-Desuggestopedia is the application of Suggestology, i.e. the scientific foundations of the methodology liberating the untapped reserve capacities of the human brain and psyche, in education and training. It is also the application of the theory of suggestive communication to the teaching process. It is true that SuggestopediaDesuggestopedia is a Humanistic approach to education as the Suggestopedic teacher is convinced in the potential of the students to learn. Furthermore, the former (the Suggestopedic teacher) teaches the latter (the Suggestopedic students) how to learn, i.e. provides learning patterns which the students apply consciously and subconsciously. This is a whole-brain approach as it spontaneously activates a number of students' senses in the learning process. The students themselves define the method as a brain friendly approach to learning because of that. What was particularly new and innovative at the time, i.e. $70 \mathrm{~s}$ and $80 \mathrm{~s}$ of the $20^{\text {th }}$ century was that it did and till does apply the principles of psychoanalysis in teaching focusing on the positive aspects of the personality.

It should be mentioned that Suggestopedia-Desuggetopedia is a teaching approach which respects the principles of Cognitive and Social Constructivism because the learning process flows naturally and fluently following elegant liaisons. The use of L1 is accordingly used both in written and spoken forms. L1 comes up in the textbook, called the scenario, as parallel translation of the text in the foreign language being taught, thus L1 does exist there but only as reference. It is rather restrictedly used in speaking during the lessons. What is also characteristic of Suggestopedia-Desuggestopedia are the following: strategic interaction, scenario-based instruction, collaborative learning and integrated curricula. At the time of considerable school stress, fatigue and boredom Suggestopedia-Desuggestopedia was the savior of students, the emancipation of 
learners from teachers and school curricula, or the emancipation of the learner and the teacher from the school specific limitations and neuroses related to school, the so called 'didactogenic diseases'. Suggestopedia-Desuggestopedia did not obey the social suggestive norms, those norms suggested by the authorities that learning is difficult or sometimes impossible, and by all means laborious and unpleasant.

Before focusing on the elaboration techniques themselves it will be practical to briefly review the seven Suggestopedic laws, because the former appears to be tightly linked to the latter. Here they are:

1. Active love for the human being. The reserves of a personality can be discovered, recovered and activated only by means of love. Love is present at the very beginning when the teacher delicately involves the students in a game in which he/she acts together with them, just as a mother plays with her children. That game will continue throughout all the stages, in different forms, to the end of the course.

2. Freedom of personality. Freedom of personality and personal choice is well respected. Nobody has ever been programmed in terms of time and activity. Everybody has their own free and conscious self-control and will.

3. Conviction of the teacher in the final results. This is the conviction that something extraordinary, different from the social suggestive norm, is taking place with no failure, and will lead to the state of inspiration of the teacher. The students have the feeling that they achieve everything on their own.

4. Manifold increase of input volume. The study material presented to students in a specific time frame, must be, as a minimum, at least 2 to 3 times (times, not percent) larger in size than the existing established norm by the other methodologies.

5. Global-partial, partial-global; partial through global. In SuggestopaediaDesuggstopedia those two are acquired simultaneously. Never acquire first the elements, and then their union in meaningful units. Acquire simultaneously the element and its place in the meaningful units.

6. The golden proportion. The golden proportion has been for centuries recognized as the greatest harmony in nature. The formula of the golden proportion is the following:

$$
\begin{aligned}
& (a-x) / x=x / a \\
& x^{2}+a x-a^{2}=0 \\
& x=0,6180339
\end{aligned}
$$

7. Use of classical art and aesthetics. Suggestopedic art creates conditions for optimal psycho-relaxation and harmonious states which help create a spontaneously increased acquisition state and enhance the capacity to tap the reserves of mind in a pleasant atmosphere. 
The above mentioned laws need to be observed at any stage of the Suggestopedic teaching-learning cycle. For the purposes of the present article here are the stages of the quoted cycle: Introduction, Concert sessions, Reading, Elaboration, and Production.

Obviously, Suggestopedic teachers need to be knowledgeable as to what elaboration techniques to apply at the stage of elaboration. They can choose from a number of techniques:

1. Commenting on initial quotations. A Suggestopedic-Desuggestopedic textbook, called the scenario, contains a great number of quotes by famous people of literature, e.g. Shakespeare, Byron, etc. Such quotes require from students to give arguments and express opinion. The teacher guides the discussion focusing on topical grammar, vocabulary and useful functional expressions (agreeing, disagreeing, offering, rejecting, asking for information, etc).

2. Introducing antonyms and synonyms of a word. By asking for or offering synonyms and antonyms the Suggestopedic teacher helps the students to revise, learn new items and build vocabulary nests.

3. Introducing derivatives of a word. The students learn to effectively use different parts of speech and place them in their appropriate places in the sentences. Consequently, apart from learning new words students naturally start to make up their own correct sentences without putting additional efforts into theoretical rules.

4. Introducing idioms and/or phrasal verbs. Normally there is a glossary of expected new vocabulary after the main text.

5. Changing the facts in short paragraphs. The Suggestopedic teacher always provides the model and suggests options for the word changes, e.g. proper names, professions, nationalities, family relatives, places in town, sights, landmarks, prepositions of place, colours, verbs, i.e. factual information.

6. Changing the view point of a paragraph. This type of exercise aims at practicing and consolidating mainly grammar rather than lexis. For example, the teacher ask the students to change the view point from I into he/she, or from we into they. It is also practical to assign one and the same paragraph to different students to read from the point of view of different characters.

7. Games are fantastic for both beginners and advanced students. The latter equally enjoy competitive and non-competitive games. The learners take part in games, songs, and gymnastic exercises which help students regain self confidence, spontaneity and receptivity.

a/ Games on paper cards I require that students put jumbled words in the correct order to form meaningful sentences which teach polite requests, asking for information, agreeing, disagreeing, i.e. functional language. 
b/ Games on paper cards II require that students fill in the gaps (in two or more teams) in sentences taken from the lesson. The teacher may feel free to organize a competition between the teams.

c/ Quotations seem to be a credible source of information in terms of grammar, vocabulary, general knowledge. Teachers will find it very practical to use quotations by famous people for reported speech.

d/ Paper jumbled letters are a fantastic game for both children and adults to form familiar words which appear in the lesson.

e/ Teachers can suggest a very long word consisting of different letters to encourage students to form a number of shorter words using the letters in the former. this game can be arrange as a completion between teams.

$\mathrm{f} / \mathbf{A}$ jumbled story, i.e. a summary of the lesson. The teacher writes each sentence on a separate card and prepares two or three sets of jumbled stories for two or three teams who compete for time. The winning team receives an award.

$\mathrm{g} /$ Forming clusters of words with the same diphtongues is a game appropriate for advanced students.

$\mathrm{h} /$ Forming clusters of words with the same core vowel is an effective game that consolidates correct pronunciation.

i/ Forming clusters of words with the same silent consonants teaches students to differentiate and practice correct pronunciation.

j/ Topical discussions may be considered as part of the elaboration stage as well as the production stage because this is when the students will activate their accumulated vocabulary and acquired grammar knowledge and employ them into real-life situations or up-to-date debates. For example, students are assigned to decide on legal and illegal items at the customs. They will need to use the terminology of the lesson. Another example of a topical discussion is deciding on practical tips of how to work better. Students use functional language for agreeing/disagreeing, giving reasons, and adding information to the list.

$\mathrm{k} /$ Project work can be considered either as an elaboration technique or as a production stage because this is when students demonstrate to what level they have acquired the foreign language.

I/ Role plays can be considered either as an elaboration technique or as a production stage for the same reason mentioned above. Apart from acquisition of new grammar and lexis the students have an excellent opportunity to reveal how artistic they can be. Students are asked to pretend that they are someone else and assume different personalities and perform in the target language as if they were those persons. They are sometimes asked to create their own lines relevant to the situation.

The above mentioned elaboration techniques prove effective as well as enjoyable for the students. The former need to provide for and boost students' motivation and confidence, 
that the latter have been doing well, and are definitely making a progress. There is a subtle balance between

The elaboration techniques prove even more effective if the classroom arrangement brings about establishing a relaxing and reassuring atmosphere because the learners learn not only from the effect of direct instruction but from the environment in which the instruction takes place.

We perceive much more in our own environment. Posters and various visual materials are designed and used so that the students can absorb and perceive the necessary facts and knowledge effortlessly, even if their attention is not directed to them. This is called the effect of peripheral perceptions.

The elaboration techniques enable the students to engage in various activities that help them learn the new material and use it spontaneously. Those activities are varied as mentioned above and allow the students neither to focus on the strictly linguistic message solely, nor feel boredom. In actuality, the communicative intent comes up to the conscious surface.

Furthermore, the Suggestopedic elaboration techniques contribute to students' learning a language approximately three to five times as quickly as through conventional teaching methods. They also can arouse students' interests and potential to memorize.

A very playful and true reference to Suggestopedia-Desuggestopea is the following acronym:

- Stimulates the whole person

- Undoes blocks

- Goes rapidly forward

- Gives creative solutions

- Encourages relaxation

- Strengthens self-esteem

- Iends to all the senses

- Optimizes learning 
- Propagates talent

- Enhances learning

- Dramatizes material

- Includes pictures, music, songs and movement

- Addresses the whole person!

\section{References}

Lozanov, Georgi. 1997. Suggestology and the Outlines or Suggestopedia, New York: Gordon and Breach.

Lozanov, Georgi. 1978. Suggestology and Outlines of Suggestopedy. Philadelphia, PA: Gordon and Breach.

Lozanov, Georgi and Evelina Gateva. 1988. The Foreign Language Teacher's Suggestopedic Manual. New York. Gordon and Breach.

Gateva, Evlina. 1991. Creating Wholeness through Art. Global artistic Creation of the educational Training Process, Aylesbury, UK: Accelerated Learning Systems.

Bowen, T., What is Suggestopedia?, Macmillan PublishersLtd., 2002

Iki, Setsuko. 1993. Interview: Georgi Lozanov and Evelina Gateva. The Language Teacher 17/7:3-17

Richards, J.C. and Rodgers, T.S. (2001). Approaches and Methods in Language Teaching (2nd ed.). Cambridge: Cambridge University Press. 